\title{
RESPONSABILIDAD DEL POETA Y SENTIDO RELIGIOSO DE LO PERMANENTE EN LA POESÍA DE LA MODERNIDAD*
}

Dr. Américo Ferrari

"¿Y para qué poetas en tiempos de penuria? » se pregunta en el umbral del siglo XIX el gran poeta alemán Friedrich Hölderlin en su poema "El pan y el vino» «Durftige Zeit » : tiempos de penuria en el sentido de pobreza e indiferencia espiritual : y responde él mismo en otro poema : porque ellos fundan lo que permanece, «sacerdotes sagrados que van de tierra en tierra por la noche sagrada ". Fundan lo que permanece : es decir, buscan y rescatan un núcleo de eternidad en la fragilidad de la palabra, que es, dice el mismo poeta, lo más inocuo y lo más peligroso, y a través del tiempo que nos disgrega y nos cambia de minuto en minuto; porque, dice Nietzsche, otro poeta, « todo deseo quiere eternidad, quiere profunda, profunda eternidad ». En esta busca y esta fundación por la palabra de lo permanente y de lo eterno a través y más allá del tiempo, radica la responsabilidad del poeta frente al hombre del mundo moderno, rehén impenitente de la efímero, lo transitorio y lo temporal. La responsabilidad está en la necesidad de responder al interrogante que nos plantea el destino del hombre, ser temporal, frente a la eternidad; y de responder del propio sentido de la poesía. Por eso voy a enfocar ahora la cuestión de la poesía frente al mundo moderno desde el punto de vista de la carga de sentido religioso que hay en los poetas de la modernidad.

Aclaremos Ios términos. En primer lugar «poesía de la modernidad» quiere decir aquí poesía contra la modernidad y su carencia de sentido religioso. $\mathrm{La}$ palabra «modernidad» es moderna : la difunde Charles Baudelaire hacia 1850 para referirse a la vida y las costumbres y su influjo sobre la sensibilidad del poeta en lo que era en aquella época la ciudad moderna por excelencia, París, que Walter Berjamin ha calificado de «capital del siglo XIX » : las innovaciones, el cambio y la variación incesantes de los modos tradicionales de vida y la rápida destrucción de las formas mismas de la ciudad : « moda " y "modernidad » resultaban entonces términos gemelos. El adjetivo "moderno ", en cambio es, antiguo y ha venido a encerrar la historia de la humanidad en tres edades : antigua, media y moderna a la que viene a añadirse la « contemporánea » que no se sabe muy bien qué indica pues

\footnotetext{
Ponencia - Lima 4 de noviembre 1998
} 
pues uno es siempre contemporáneo del tiempo en que vive. Finalmente se acuñó el término "posmodernidad " para designar el fin de la "modernidad " y la crítica de sus mitos después de las dos guerra mundiales y en medio del vértigo social, económico, cultural y espiritual de nuestra época. Asi que se trata de enfocar la modernidad y la poesia a través de las diversas etapas de la llamada edad moderna: desde sus raices en el Renacimiento; siglos XV-XVI, hasta la segunda guerra mundial y la reacción que provocan en algunos grandes poetas el materialismo creciente y las revoluciones económicas, políticas y culturales de los siglos XVIII y XIX, hasta la crisis del mito de la modernidad en nuestro siglo, con el cuestionamiento de la creencia materialista en el progreso y en la salvación del hombre en la historia y la sociologia, las ciencias y las técnicas.

Por otra parte, entenderemos usentido religioson en su acepción más amplia y general, o sea la que abarca una visión trascendente de la vida espiritual y una intuición o un anhelo de la presencia de la divinidad entre los hombres que puede ser también, en más de un caso, un sentimiento angustiado y desolado de su ausencia. En efecto, la ausencia de Dios en el mundo moderno y, por carambola, la presencia invasora de la nada, es un dato insoslayable para seguir la evolución del pensatmiento poético y filosófico desde el Renacimiento pero de una manera más evidente desde finales del siglo XVIII y principios del XIX con el romanticismo alemán en especial, y con una figura como la de Giacomo Leopardi en Italia. Veremos asi que, paradójicamente, se puede extraer una carga religiosa de la obra de más de un poeta moderno considerado « ateo » o agnóstico.

Lo que podemos llamar la poesía propiamente religiosa occidental florece sobre todo en la llamada edad media. Pero este espiritu religioso declina ya en el Renacimiento, sobre todo a partir del siglo XVI. La excepción es España, donde precisamente en el siglo XVI, con la contratreforma que cierra las puertas de España a la influencia del protestantismo, se dan algunos de los mayores misticos del mundo y una poesía impregnada de hondo sentido religioso : San Juan de la Cruz, Fray Luis de León, Santa Teresa de Jesús; y aún en el siglo XVII, cuando buena parte de Europa se orientaba ya a la indiferencia religiosa, este sentido religioso de la vida se manifiesta todavia en Quevedo, en Calderón, y sobre todo en algunos bellísimos sonetos de Lope de Vega. Para no quedarnos en un catálogo abstracto, por su belleza y como ejemplos de la persistencia del sentido religioso cristiano en una Europa que lo perdia rápidamente, leeré dos de ellos, a Jesús y a su cruz, que no llevan titulo: ¿Qué tengo yo que mi anistad procuras, / qué interís se te sigue, Jesuis mio / que a mi puerta, cubiento de rocio, pasas las noches del invierno oscuras? // iOb cuánto fueron mis entrañas duras, / pues no te abri! / Q Que extraño desvario, / Si de mi ingratitud el bielo frío/ Secó las llagas de tus plantas puras! / / Cuántas veces el ängel me decia : "Alma, 
asómate agora a la ventana: / Verás con cuánto amor llamar porfia ! / Y Ycuántas, bermosxra soberana, / "Mañana le abrinimos, „ respondia, / Pana lo mismo responder mañana!'; y el segundo: Pastor, que con tus silbos amorosos / Me despertaste del profando sueño: / Tü que biciste cayado de ese leño / En que tiendes los brazos poderosos; / Vuelve los ojos a mi fe piadosos, / Pues te confieso por mi amory dueño, / Y la palabra de seguirte empeño, / Tus dulces silbos y tus pies bermosos. // Oye, Pastor, que por amores mueres, / No te espante el rigor de mispecados, / Puestan amigo de rendidos eres; // Espera pues, y escucha mis cuidados; / Pero zcomo te digo que me esperes, / Si estás, para esperar, Los pies clavados? Es dificil imaginar que en la Europa de la época pudieran escribirse aún poemas cargados de tanto sentido religioso. En cambio, en el siglo XVIII España entra, ya bajo el gobierno de los Borbones, en la fila de los países occidentales racionalistas, « ilustrados 》 y progresistas, o sea, en la "modernidad", pero a la cola ; y deja de crear poesía.

Volvamos a la primera modernidad, la del Renacimiento italiano, finales del siglo XV y el siglo XVI, que ejerció su influencia sobre toda Europa. En Italia se dan entonces algunos de los mayores poetas del mundo occidental de la época, como Ludovico Ariosto y Torquato Tasso, pero no se puede decir que estén marcados por un sentimiento religioso, por lo menos de uno que aflote en su poesia. En el siglo XVII se acentúa el carácter meramente estético de la poesía, en Italia con Gianbattista Marino y el marinismo, en España con Luis de Góngora y el culteranismo, modelos de poesia barroca donde el aspecto estético del poema, el esplendor y la belleza de las palabras, las imágenes y la música verbal en que flotan se bastan a sí mismos y se agotan en sí mismos; es decir que aquello de lo que habla el poema, su "sentido ", es insignificante : la brillante y compleja ornamentación de la poesía barroca recubre un espacio vacio, no refiere a nada, refiere a la nada, lo que no deja de tener un sentido metafisico, seguramente sin que sus autores lo quisieran o fuesen conscientes de ello. Es interesante observar que el escritor bilingüe peruano del siglo XVII Juan Espinosa Medrano, sacerdote y teólogo de origen quechua, comentando, defendiendo y ensalzando la gran poesía de Góngora y su carácter profano y limitado a la ernoción estética, dice que no hay que confundir a los poetas con los profetas y que no se puede pedir que el poema " tenga los sentidos de la Sagrada Escritura " ni oculte sacramentos y misterios inefables. La diferencia entre la escritura humana y la revelada a teológica está en que la última habla del misterio en un lenguaje sencillo, mientras la poesia profana, elocuente y recargada de ornatos, "yace vana, hueca y vacia, sin corazón de misterio alguno »... « [T] oda el alma Poética », termina diciendo Espinosa Medrano, « es poco más que nada " (Espinosa Medrano, 1938: 80). O sea es NADA, y el "poco más » añadido a esta nada es sencillamente la belleza de la palabra, el hechizo de las imágenes y el sonido. Es preciso recalcar aqui que tanto el autor, Góngora, como su comentador y admirador, Espinosa 
Medrano, eran ambos eclesiásticos y el segundo teólogo, autor de autos sacramentales de evidente sentido religioso en quechua y en castellano, lo que no le impide, en el plano estético, profesar la mayor admiración a la poesia "vana, hueca y vacía » de la modernidad bartoca que surge precisamente en España y repercute con tanta fuerza en el Perú, al lado de lo que subsiste de poesía religiosa y mistica

De otra modo, con la excepción de España, lo poco que queda de sentida religioso en la poesía del siglo XVII habrá que buscarlo fuera de los países llamados latinos, en la obra del poeta místico alemán Angelus Silesius, luterano convertido al catolicismo. Su pensamiento se inspira en la obra del Maestro Eckart, gran místico alemán de los siglos XIII-XIV. De Angelus Silesius se cita a menudo el verso La rosa es porque es; florece porque florece. La rosa que florece es sencillamente un regalo de Dios o el símbolo de todos los regalos de Dios y no hay nada que preguntar acerca de ella. De la misma manera tres siglos después el poeta peruano Martín Adán evocando a Dios dirá: «el que creó el latido porque late ». El otro místico alemán importante para el movimiento poético y espiritual en Europa en la transición del siglo XVIII al XIX es Jacob Böhme, quien, aunque nunca escribió poemas, tuvo una marcada influencia en algunos de los primeros románticos.

En Italia y en Francia no hay prácticamente poesía que tenga alguin sentido religioso y ni siquiera simplemente poético en el siglo XVII, salvo un par de tragedias del poeta dramático Jean Racine aunque sí hay aún un importante pensamiento filosófico cristiano, hondamente religioso, representado por el gran escritor y científico, también francés, Blaise Pascal. Eso es todo. En el siglo XVIII en cambio, el siglo de las luces o de la ilustración, no hay nada : hay sí notables escritores y versificadores, como Voltaire, Rousseau y Diderot en Francia, Metastasio, Giuseppe Parini y Vittorio Alfieri en Italia: eran escritores notables porque escribieron de manera notable, pero no se les puede calificar de poetas. Ia literatura de la ilustración es antipoética, estrechamente racionalista y ajena a las cuestiones metafisicas y al misterio. Hay que volverse pues a otros horizontes y esperar los albores del romanticismo para encontrar una reacción a esa modernidad que, encerrada en el círculo del imperativo económico, la razón política y la ideologia, hace del hombre moderno con su diosa razón la medida de todas las cosas e incluso de todo lo que no es cosa, pero lo que no es cosa por lo general ellos no lo ven.

Quizá, paradójicamente, el último avatar de la modernidad que provocó en Europa la revolución francesa tuvo por consecuencia precipitar en Alemania y 
sobre el terreno ya labrado por el pietismo una fuerte reacción contra el moderno racionalismo burgués; reacción que se produce precisamente con el advenimiento del romanticismo alemán. Haré notar de paso que en Francia, salvo alguna excepción, no hubo un verdadero movimiento romántico. La reacción a la que me refiero se dará, en el plano literario, en Inglaterra, con la obra poética y también plástica de William Blake, raro poeta místico y visionario; pero sobre todo en Alemania con los primeros románticos, Novalis en especial, y con un gran genio poético que sin ser exactamente un romántico, tiene ya la sensibilidad romántica sobre un fondo de pasión delirante por las representaciones religiosas del mundo antiguo: Grecia y sus dioses. Este genio poético es Friedrich Hölderlin, que ya he mencionado. Subrayemos que en Alemania, en la edad moderna, como hemos visto, la poesia y el pensamiento de fondo religioso tenian ya una tradición desde el siglo XVII con Angelus Silesius y los escritos de Jakob Böhme.

Me permitiré recordar ahora brevemente algunos nombres de la poesía alemana del siglo XVIII y el XIX que cronológicamente preceden a los dos de sensibilidad romántica ya nombrados : Hölderlin y Novalis. Casi todos ellos son grandes poetas nacidos entre el decenio de los 20 y el decenio de los 50 del siglo XVIII, es decir en aquella época cuando la poesia, con sentido religioso o sin él, en España, Francia e Italia brillaba por su ausencia. El primero de estos clásicos alemanes es Friedrich Gottlieb Klopstock, autor de La Messiada, poema largo que natra la epopeya de Jesucristo, el Mesias. Recordemos que en el Perú, en el siglo XVI, el poeta Diego de Hojeda, sacerdote dominico nacido en Sevilla y radicado y muerto en Lima, escribió y publicó un poema épico-religioso, $\mathrm{La}$ Cristiada, publicado en Sevilla en 1611, que narra en 12 cantos la pasión y muerte de Jesús. Se ha escrito que La Cristiada de Hojeda sirvió probablemente de modelo a La Messiada de Klopstock (L.A. Sánchez, $1974 ; 119$ ). La critica ha visto en el patetismo y la devoción intima de los versos de Klopstock una influencia del pietismo, movimiento religioso que surgió en la segunda mitad del siglo XVII en el seno del luteranismo y que constituye una reacción contra el dogmatismo y el carácter demasiado institucional de las iglesias, y destaca la relación personal e intima de cada persona con Jesucristo. Kant, Novalis y otros filósofos y poetas alemanes de la época, fueron pietistas o estuvieron influenciados por el pietismo. Klopstock representa en cierto modo el clasicismo alemán, tardío, pues el Renacimiento artístico italiano que se extendió a España y Francia en el siglo XVI no penetró en la Alemania de Lutero. Mientras que, al contrario, entre los siglos XVI y XVII Inglaterra, también reformada y protestante, daba una pléyade de grandes poetas, entre ellos Shakespeare. Pero hay que tener en cuenta que la reforma inglesa se debió a motivos políticos y nupciales más que verdaderamente religiosos. Después de Klopstock se inicia la reacción anticlasicista con el 
movimiento Sturm und Drang (Tormenta e Ímpetu). Los dos poetas principales que precedieron a Hölderlin y a los románticos, Goethe y Schiller, tenian entonces 27 y 17 años. Los dos estuvieron vinculados a ese movimiento en la primera etapa de su obra. La poesía de Goethe abarca muchos temas y toca muchas formas, y el tema religioso se encuentra principalmente en las dos partes del Fausto, drama en el cual uno de los tres personajes principales es Mefistófeles, el diablo, a quien Fausto vende su alma en cambio de una segunda juventud. En una escena Mefistófeles dialoga con Dios y da de sí mismo la definición probablemente más exacta que se haya dado del espíritu del mal : "Yo soy el espíritu que siempre niega ». Al final del primer Fausto Margarita, la inocente muchacha seducida por Fausto bajo la guía de Mefistófeles, ya al borde de la muerte, invoca a Dios y a los ángeles : «Tuya soy, joh Padre! [Sálvame ! / ¡Y vosotros, ángeles, santas legiones, rodeadme, protegedme ! // Mefistófeles : !Está condenada ! / Voz (de las alluras) : Está salvada !. Este es èl fin de la primera parte de la tragedia. Al final del segundo Fausto, cuando al morir éste escapa también a las garras de Mefistófeles, hay una escenificación impresionante que reúne a los espíritus celestes, coros de los ángeles, coto de los niños bienaventurados, coro de las penitentes, y finalmente la Madre gloriosa y el Doctor mariano que la implora : « Virgen, madre, reina, diosa : consérvanos tu clemencia ». Y el coro místico cierra la tragedia con unos versos que han quedado entre los más célebres de la literatura occidental : «Todo lo transitorio / Es sólo alegoria ; / Lo inaccesible se vuelve aquí suceso; / lo indescriptible se hace realidad. / Lo eterno femenino nos atrae hacia arriba ».

Friedrich Hölderlin, como ya he dicho, es uno de los más importantes poetas alemanes. Poéticamente parece encontrarse en el fiel de la balanza entre clasicismo y romanticismo; su nostalgia de los dioses antiguos y el entusiasmo que le inspiraban Grecia y su mitologia, por una parte, y la revolución francesa por la otra, parecen situarlo en la modernidad de la época, pero al mismo tiempo en una antigüedad religiosa, precisamente por religiosa no recuperable ni comprensible para la mentalidad cientista, positivista y progresista de la burguesía moderna para la cual la modernidad suponía en el fondo la liquidación de los valores espirituales vinculados con la religión, aunque fuera la de los dioses antiguos, si un poeta los sentía como dioses y no como simples alegorias. En todo caso los dioses se han retirado a sus moradas y el hombre moderno está solo, pero volverán y en esa aspiración o esperanza estriba buena parte del sentido religioso de Hölderlin que invoca con frecuencia al Padre, el Padre augusto, el Alrísimo o Padre eterno pero este Dios Padre se figura a menudo como el Padre Éter de la Grecia antigua. En realidad la visión de la divinidad en este poeta es ambigua : las representaciones de los dioses de la antigüedad se entretejen con representaciones cristianas, dándonos una visión sincrética de la revelación divina entre la eternidad y la 
historia que culmina en la poesía de Hölderlin con el advenimiento de Cristo : a Tantos acontecimientos se producen / Y todos sin efecto pues somos insensibles, somos sombras hasta que / Nuestro Padre el Éter reconozca a todos y a todos pertenezca. / Mientras tanto adviene, llevando una antorcha entre las sombras, / el Hijo del Altísimo, el Dios sirio. / Los sabios bienaventurados lo ven; de las almas prisioneras / Sube y brilla una sonrisa y sus ojos se abren a a la luz».ElDios sirio es Jesucristo, llamado sirio porque la Siria de la antigüedad incluia parte del territorio de la actual Palestina, donde nació Jesús. Asi concluye esta larga elegía que lleva significativamente por titulo " El pan y el vino": las dos especies de la Eucaristia. Pero donde más se revela cl aspecto propiamente religioso-cristiano de Hölderlin es en el Himno a la Madona ( $" \mathrm{Oh}$ cuánto he sufrido / por ti y por tu hijo, / Oh Maria »), también en el himo titulado "El Único " (el único es Jesucristo), pero sobre todo en el himno "Patmos», la isla griega donde San Juan escribió el Apocalipsis y que, después de la evocación de aquella isla, es sobre todo un himno dedicado a la última cena, a la pasión de Cristo y a la fidelidad de los apóstoles. En este poema el Padre no es ya el Éter sino visiblemente el Dios de los cristianos con una referencia explícita a las Escrituras : " Lo que prefiere el Padre que reina sobre todas las cosas / es que se respete la letra inmutable y que se interprete / con cuidado todo lo que permanece / Y a ello se amolda la poesía alemana "; dice el poeta para concluir su himna. Hölderlin naufragó en la locura, no cumplidos aún los 40 años.

De todos los poetas de la época, sin embargo, el más impregnado de sentido poético-religioso, y el que más fuerte y hondamente reaccionó contra el descreimiento del siglo llamado «de las luces», fue el barón Friedrich von Hardenberg, que adoptó el seudónimo Novalis, uno de los genios del romanticismo. Dejó dos libros de poemas, Himnos a la nocbe y Cánticos espirituales o simplemente, Cánticos, composiciones de tema religioso para cantar en las iglesias, además de un puñado de poesias sueltas. Pero en realidad, toda la obra en verso o en prosa e incluso la vida de Novalis es poética y también religiosa. En realidad para este poeta todo era poesia y había hecho de este término un sinónimo de realidad absoluta o de la busca de dicha realidad. : "La poesía es lo absolutamente real, Tal es el núcleo de mi filosofia. Cuanto más poético más verdadero ». "Y la religión misma es poesía práctica», dice en uno de sus fragmentos.

En Himnos a la noche la noche es el recinto místico del amor, de la embriaguez, del sueño, el éxtasis religioso, la eternidad, la unidad, la infinitud, la ausencia de límites, el lugar de la muerte que para el cristiano es la verdadera vida ; mientras que la luz representa la acción, la actividad cotidiana y práctica, el reloj. En los Himnos noche y día, oscuridad y luz simbolizan términos contrapuestos que 
rigen el tiempo de los hombres en esta vida terrestre ; pero en realidad lo que el poeta intuye es una visión superior en que luz y sombra se anulan en el seno del absoluto en una unidad que se representa por la claridad divina : Cuando la luzy la sombra se acoplen de nuevo para engendrar la pucra claridad, dice en un poema. Lo que busca Novalis y lo que anhela, según él, el hombre es el absoluto, que en alemán se dice " das Absolute " pero también « das Unbedingte ", término filosófico, del verbo bedingen, formado sobre Ding : cosa, que se emplea corrientemente en el sentido de condicionar, motivar, depender de ; y asi, haciendo un juego de palabras, Novalis dice : « Buscamos por doquiera el absoluto (das Unbedingte $;$ lo no " cosificado ») y sólo encontramos cosas (Dinge) ». Los Himnos a la nocbe son una etapa de esa busca más allá de las cosas. Igual que Hölderlin Novalis, en el Himno $\mathrm{V}$, plasma en una visión sincrética e intemporal la historia mítica de la religión y las religiones, y del advenimiento de lo divino. Esta historia se inicia con el reinado del destino, después viene la edad de oro cuando hombres y dioses convivian en una especie de paraiso terrestre. Pero viene la muerte y un "viento del norte " ahuyenta a los dioses que se refugian en la noche hasta el advenimiento de Cristo: "El mundo nuevo se manifestó con un aspecto nunca visto en la poética choza de la pobreza Un hijo de la primera mujer virgen y madre fruto infinito de un arcano abrazo ». Y finalmente la muerte y la resurrección de Cristo : «En medio de horrenda angustia se acercaba la hora del nacimiento del mundo nuevo. Duramente luchó con las ansias de la vieja Muerte y luego, tocado por la mano liberadora del amor eterno, se durmió " (...) " Despertó revestido de nuevo y divino esplendor y ascendió a las alturas del mundo que acababa de nacer enterró con sus propias manos el cadáver del mundo viejo en la tumba que él abandonara y con su omnipotente mano fijó sobre ella la piedra que ya ninguna fuerza será capaz de levantar " (...) Largos siglos han transcurrido desde entonces y con renovado esplendor gira el nuevo mundo que creaste y por millares los hombres ya libres de dolor y tormento han ido hacia ti con fe con fervor y constancia reinan contigo y con la Santa Virgen en el reino del amor ofician en el templo de la divina muerte y son tuyos por la eternidad w. Los temas de los Cánticos son la piedad; la vida, muerte y resurrección de Jesucristo, María Magdalena, la venida del Espiritu santo, y se destaca en general en estas composiciones como en toda la obra el culto a la Virgen Maria, que absorbe en la poesia de Novalis la figura espiritual de su novia Sophia von Kühn muerta a los 15 años. Igual que el Fausto de Goethe la evocación de Maria, la Madre gloriosa, y la devoción a lo etemo femenino coronan la obra poética.

Novalis muere a los 29 años en 1801 apenas iniciado el siglo XIX. En el umbral también del mismo siglo, nace en Italia uno de los más grandes poetas del mundo moderno, Giacomo Leopardi, espiritu tan sediento de absoluto como 
Novalis pero al revés. «Al revés » quiere decir que, así como el poeta alemán busca el absoluto y sólo encuentra cosas, y entonces apuesta contra las cosas y por el Ser, el italiano, en su propia búsqueda del absoluto y del infinito, lo que encuentra ante todo a través de las cosas es la Nada. En la historia mítica del mundo que presentaba Novalis, los dioses desaparecen y queda la naturaleza inerte y solitaria. Entonces huye la fe con sus conjuros y huye « su divina compañera, la imaginación que todolo transforma y todo lo hermana ». Lo mismo ocurre en Leopardi, y este quedarse solo del hombre natural frente al "número árido y la estricta medida ", ahí donde la imaginación ya no diviniza nada porque la razón de la modernidad la ha matado, se resuelve en la obra de Leopardi en el sentimiento de la nada: es éste un concepto clave que se extiende por todo el siglo XIX hasta nuestros dias a partir de Leopardi y desde que el filósofo cristiano Sören Kierkegaard definió la angustia como el sentimiento de la nada : esta presencia obsesiva de la nada constituye uno de los principales síntomas a la vez de la culminación del reinado de la modernidad y de su disolución en la transición del siglo XIX al XX. «Sobre nosotros, desde la cuna, se cierne inmóvil y hasta la tumba, la nada ", dice Leopardi en uno de sus primeros poemas, contraponiendo el hombre de su época sobre la que "se cierne tanta niebla de tedio " a un pasado en que la imaginación, hoy muerta, elevaba al hombre a visiones sobrenaturales o maravillosas ; y así el hombre moderno queda encerrado entre la fria razón y la naturaleza despiadada, (madre en el parto y en el querer madrastra "; es lo que en la obra de Leopardi se presenta como il vero, la verdad, que le prohíbe al hombre conquistar una trascendencia en la imaginación y en la creencia en un más allá. La ausencia de Dios o su ocultamiento deja paso a la presencia del hado o destino: « il fato " : la palabra « fato" aparece 70 veces en la obra poética de Leopardi; la palabra Dios ni una sola vez ; solamente los " dioses " : cuatro veces. Es seguramente la angustia ante la soledad del hombre en una tierra que ya ningún dios frecuenta o consuela, el vivo sentimiento de la ausencia del Ser constatable en la presencia de la $\mathrm{Nada} \mathrm{lo}$ que pone en la poesía de Leopardi una evidente impronta religiosa. Qué nada toco / en todo, dirá un siglo después el gran poeta argentino Oliverio Girondo. Ahora, al hablar de la poesía italiana en la época de Leopardi no se puede omitir una referencia a un notable escritor y poeta católico, Alessandro Manzoni, autor de la conocida novela histórica Los noviosy de unos Himnos Sacros, como los cánticos de Novalis, pero menos intimos en el sentimiento y más retóricos en la forma.

Y después de esto desembocamos en la crisis que sufre la modernidad entre la segunda mitad del siglo XIX y la primera del siglo XX, y que se revela con rasgos marcados en la angustia y las convulsiones de la poesía de la época. Lo podemos ver en dos genios poéticos, el último también filosófico: Baudelaire en Francia, Nietzsche en Alemania. Charles Baudelaire es el primero que ha tratado 
de definir la modernidad tal como él la veía en su tiempo, dedicándole un subcapítulo de su libro sobre el arte, Curiosidades estéticas. Este capitulo se llama a secas « La modernidad " y en él el poeta aborda este concepto no con el significado de la praxis $y$ las ideologias del progreso a ultranza que caracteriza a la edad llamada moderna, sino como uno de los dos extremos del arte : « la modernidad es lo transitorio, lo fugitivo, lo contingente, la mitad del arte, mientras que la otra mitad es lo eterno y lo inmutable». Para el artista se trata de « sacar de la moda lo que ésta puede contener de poético en lo histórico, de extraer lo eterno de lo transitorio ». Es así como el poeta trata de captar en el poema el instante huidizo, el suceso aparentemente banal; unas viejitas que pasan por la calle, un cisne que se ha escapado de su jaula y arrastra su plumaje blanco por el asfalto de París, etc. En eso que está sucediendo ahora radica la " modernidad » y la poesía exige detener ese instante, como quiere el Fausto de Goethe que exclama: « $\mathrm{Al}$ instante yo debería decirle : detente, eres tan bello \%, El instante detenido nos abre la eternidad. Por eso dice Baudelaire que hay una modernidad para cada pintor antiguo. Cada artista de cada época es moderno dentro de su modernidad. En el poema "Los faros", Baudelaire evoca a ocho grandes artistas que jalonan la historia de la pintura del siglo XV al siglo XIX, de Leonardo a Delacroix, todos marcados por la impronta de Dios, y termina con esta estrofa : «Pues realmente, Señor, es el mejor ejemplo / Que se pueda aducir de nuestra dignidad / ese largo sollozo que rueda por el tiempo / Y va a morir a orillas de vuestra eternidad \%. Y en la presencia de esta eternidad inseparable de nuestra temporalidad está sobre todo el sentido religioso de la poesía de Baudelaire, asi como en la contienda angustiosa que, según él, se da en el alma de cada hombre entre dos postulaciones simultáneas, una a Dios, la otra a Satanás, contienda terrible en el alma del poeta y que desgarra angustiosamente su poesia.

A primera vista ni Dios ni Satanás parecen existir en la obra filosóficopoética de Friedrich Nietszche, anticristiana y aparentemente antirreligiosa : niega a Dios, niega toda moral, "idiosincrasia de decadentes guiados por la intención oculta de vengarse de la vida » e instaura en su lugar valores meramente instintivos y vitales la fuerza, la astucia, la crueldad : y la eternidad divina es reemplazada por el concepto de eterno retorno : la esencia del ser es la voluntad de poder y todos los valores tanto del cristianismo como de la modernidad burguesa son síntomas de la decadencia de la moderna sociedad occidental : la religión cristiana se ve metida en esta modernidad por oposición a las sociedades míticas antiguas, que desde el punto de vista religioso se representan sobre todo en Nietzsche por el dios Dionysos, dios del exceso de vida, de la embriaguez, del instinto. Pero esto es lo que se lee en la superficie de una obra complejísima y tremendamente contrastada y contradictoria. En realidad hay en el fondo de la 
poesía-filosofia de Nietzsche una presencia de la persona misma de Jesucristo como la hay en Hölderlin junto a su nostalgia de los dioses griegos. « Dionysos contra el Crucificado ", dice uno de sus fragmentos, $y$ otro : «A veces me siento tan cerca de Jesucristo que lo odio \%. Como Hölderlin, Nietzsche se volvió loco en 1889, a los 45 años de edad. Ya perdida la razón, escribe una última carta a su amigo Georg Brandes y firma no Dionysos sino El Crucificado. Se puede sospechar no $\sin$ fundamento que ese Anticristo (es el título de uno de sus libros), que pensaba ser Zaratustra-Nietzsche-Dionysos como lo llama el filósofo y crítico colombiano Rafael Gutiérrez Girardot, en el fondo del corazón se sentía herido por Cristo y su cruz: ese mismo Nietzsche-Zaratustra que proclamó la muerte de Dios, ya anunciada por lo demás setenta años antes por el novelista poeta Jean Paul Richter en una escena en que el alma de un niño sube al cielo y al llegar le anuncian que Dios ya no es. Mientras Novalis proféticamente decía que el hombre moderno ha matado a Dios y que en la próxima etapa matará al hombre : o sea se matará a sí mismo en tanto que humano.

Nietzsche, poeta filósofo que es muchos personajes, dejó una huella profunda en nuestro siglo y sobre todo en la gran poesía expresionista alemana que coincide con los estragos de la historia en la primera y la segunda guerra mundial. Mientras tanto renacen generaciones de pensadores, filósofos, narradores y poetas religiosos, sobre todo católicos, ya desde la segunda mitad del siglo XIX y en nuestro siglo sobre todo, con Gerard Manley Hopkins, Gilbert Chesterton, Thomas Stearn Eliot, Graham Green, en Gran Bretaña/Estados Unidos ; con Miguel de Unamuno en España ; Leon Bloy, Georges Bernanos, Charles Péguy, Paul Claudel, Jacques Maritain, Gabriel Marcel, en Francia ; Giovanni Pascoli, Ada Negri, Giovanni Papini, Clemente Rebora entre otros en Italia. Muchos de ellos fueron católicos ortodoxos y representan sin lugar a dudas una vigorosa reacción contra la extrema decadencia de la modernidad atea y sus mitos. Tratarlos requeriria todo un curso, o varios. He preferido para esta charla abordar históricamente la irrupción de la modernidad en el siglo XVI, su evolución en los siglos posteriores y la reacción de los poetas de sentimiento religioso, muchas veces de una religiosidad contrastada y hasta heteredoxa, y que a veces huelen incluso un poco a azufre, pero que muestran el arraigo del sentido poético religioso en la literatura occidental.

Al mismo tiempo, desde la segunda mitad del siglo pasado, se extendia la doctrina del marxismo que, dice Engels, el acólito de Marx, persigue, igual que el cristianismo, la liberación del hombre, pero no en otro mundo sino en éste, en una transformación de la sociedad, que es en fin de cuentas lo que pretendia también la modernidad burguesa ; y Leopardi, Baudelaire y Nietzsche hubietan podido 
sonreírse ante esta parodia de eterno retorno que, sin embargo, despertó en un momento una fe cuasi religiosa en grandes sectores de las masas modernas. Marx escribió que la religión es el opio de los pueblos y el opiómano Engels presenta al marxismo como una nueva religión comparable al cristianismo. Y esto me da pic para terminar refiriéndome a uno de los mayores poetas universales de este siglo, el peruano César Vallejo. Católico o comunista o todo mezclado, pero en todo caso dotado de un hondo sentido religioso que aflora continuamente en su poesía, Vallejo nació en un hogar acendradamente católico en la sierra norte del Perú, el antiguo imperio Chimú. Un poeta amigo que apreciaba poco los aspectos católicos de la poesia de Vallejo me escribió una vez: «Tendrás que reconocer que no se puede ser impunemente nieto de dos curas españoles». Vallejo efectivamente lo era, y de dos abuelas indias chimús, y en su poesia persiste siempre la nostalgia del hogar perdido y del lugar natal. A lo largo de esta obra Dios es una presencia casi constante, desde Los heraldos negros, su primer libro, hasta sus poemas póstumos escritos en Europa : "Completamente. Además, [Dios! / Completamente. Además, [nadie! », y destellan virtudes tradicionalmente cristianas como la piedad, la esperanza, la caridad: "Cristiano espero, espero siempre...» dice en Trilce, su segundo libro de poesía. La esperanza de Vallejo se cifra en una redención de la humanidad que dé por fin alimento material y espiritual a todos los hombres : «Y cuándo nos veremos con los demás, al borde / de una mañana eterna, desayunados todos " y simbólicamente en la obra poética ese ir hacia la mañana eterna se figura como un regreso al ágape de la infancia, a la comida compartida que es amor compartido con los otros, comunión. Por eso, cuando en 1931 Vallejo adhiere al partido comunista y por consiguiente, en teoria, al marxismo y después en 1937, cuando a golpe de citas del Evangelio figura en su poesia la lucha del pueblo español como el posible advenimiento de la ciudad de Dios en la tierra, lo que hace el poeta es anhelar un regreso a un pasado mítico pero vivido en su infancia : « a lo mejor recuerdo al esperar » dice en un verso. Al mismo tiempo, cuando escribía esos poemas se despide de todas las ideologías, incluyendo curiosamente a San Pedro, en tanto que piedra fundamental de la Iglesia de Cristo, entre los fundadores de sistemas ideológicos : ¡Adiós, hermanos san pedros, / heráclitos, erasmos, espinozas! / "Adiós, tristes obispos bolcheviques!". San Pedro y los filósofos son, por lo menos, hermanos. Los bolcheviques tristes obispos... Hay que tener en cuenta finalmente que el pensamiento de Vallejo como el de Nietzsche, es profundamente contradictorio, contrastado y agónico. Lo dice d́l mismo : $S e$ me antoja que a través de lo que en mi caso podría conceptuarse como anarquía intelectual, caos ideológico, contradicción o incoherencia de actitudes, hay una orgánica y subterránea unidad vital ». Según el testimonio de su viuda, ya en su lecho de muerte, a finales de marzo de 1938, Vallejo le dijo \& Escribe "; y le dictó : «Cualquiera que sea la causa que tenga que defender ante Dios más allá de la muerte, tengo un defensor: Diosm. 
La poesía de la modernidad se revela así como un empeño de liberación y como una reacción contra esta modernidad y su desacralización de la realidad que rompe todos los vínculos del hombre con el misterio y la trascendencia. Y asi la idea de progreso material indefinido en que se funda resulta ser para Thomas Stearn Eliot una degradación de la Vida, de la sabiduría y del conocimiento: ¿Dónde está la Vida que bemos perdido en el vivir ? / Dónde está la sabiduria que bemos perdido en el conocimiento? / ¿Dónde está el conocimiento que bemos perdido en la información? No están. El escritor francés André Malraux dice en un libro que escribió sobre el arte : "El siglo XXI será religioso o no será ». Puede que no sea, pero si es, los jóvenes de hoy, en el umbral del milenio, tendrán que reconquistar esa Vida, esa sabiduria, ese conocimiento. En la Vida ¿Y por qué no, para los que tengan vocación, también en la poesía?.

Dr. Américo Ferrari

Poeta y critico literario Miembro de la Academia Peruana de la Lengua Universidad de Ginebra octubre de 1998 